\title{
Summary of Research on Patterns of Unearthed Ancient Woolen Fabrics in Xinjiang
}

\author{
Xiaojuan Mao ${ }^{1}$ \\ ${ }^{1}$ Fashion and Design College, Donghua University, Shanghai, China \\ ${ }^{2}$ College of Textile and Clothing, Xinjiang University, Urumqi, Xinjiang, China \\ Correspondence: Xiaojuan Mao. E-mail: maoxj916@163.com \\ Received: February 13, $2018 \quad$ Accepted: March 26, $2018 \quad$ Online Published: April 19, 2018 \\ doi:10.5539/ass.v14n5p69 \\ URL: https://doi.org/10.5539/ass.v14n5p69
}

\begin{abstract}
The woolen fabrics relics unearthed in Xinjiang have always drawn double attention of domestic and foreign professionals, which have been carrying out a series of research works in the region from the past till nowadays. With the development of the society and the progress of science and technologies, the archeological and cultural relics of Xinjiang have also gradually come to the world, on which the research cooperation between Chinese and foreign professionals also grows. Archeology in Xinjiang fabric relics has also made great achievements. With the devoted work of these experts and scholars, a large number of fabric relics unearthed in Xinjiang have the chance to be presented to the world. Through their research, I have a more comprehensive understanding of the ancient woolen fabrics unearthed in Xinjiang, as well as the patterns, historical and cultural background. It provides technical and artistic guidance on the contents, objectives and scope of the research topics.
\end{abstract}

Keywords: Xinjiang, unearthed ancient woolen fabrics, patterns

\section{Overview}

The ancient name of the Xinjiang is Xiyu (Western Region), a region where the ancient Eastern and Western civilizations meet and a hub of the Silk Road on land. With Xiyu, the transfer station of the Silk Road, Eastern and Western cultures eventually broke through the geographical shackles, country boundaries, and ethnic obstacles, thereby the process of world civilization was greatly enriched and accelerated.

The fabrics and their patterns at the time, as an important part of the exchange between the East and the West, not only enhanced the diversified life tastes and elegant life quality of all ethnic groups in history, but also broadened the aesthetic horizon of them in both East and West, of which the cultural connotation was directly linked to the human spirit, which also left for future generations a rich and precious cultural treasure.

As shown by archaeological data, the prehistoric woolen fabrics and a large number of weavings of Tang and Song dynasties unearthed in Xinjiang are the only in-kind specimen in China so far, which not only greatly enriched the library of ancient Chinese weaving specimens, but also made some remedies in terms of patterns. Therefore, it is very important to study the patterns of the ancient fabrics unearthed in Xinjiang.

\subsection{Research Significance}

The ancient woolen fabrics unearthed in Xinjiang have an immeasurable value in the history of East-West cultural exchanges. It is not hard to see from them that when China's silk products were exported far the west along the Silk Road, the western woolen products were also sold to China; The exchanges of Eastern and Western weaving products not only met the material needs of both sides, but also provided opportunity for the for each other to exchange the weaving technologies. These ancient weaving arts occupy a position that cannot be neglected either in ancient Chinese history of fabrics and in research on the history of development of ancient Chinese fabrics patterns.

The diversified woolen fabrics unearthed in Xinjiang basically reflect the general situation of the development of China's fabric arts. These fabric arts span a large history, which cover a full range of patterns. Regarding the patterns, from the geometric pattern, cloud pattern, and variant geometric pattern, Therefore, the pattern of ancient woolen cloth unearthed in Xinjiang is a microcosm of the history of the development of the pattern of ancient Chinese textiles. Therefore, to study the arts and the dyed, woven, and embroidered patterns of the 
woolen fabrics of ancient Xinjiang, it is of great important practical significance not only for the origin of the patterns of the woolen fabrics unearthed in Xinjiang, but also for the development and innovation of modern weaving and dyed patterns.

\subsection{Time and Space Category}

\subsubsection{Time Category}

Ancient, the concept of time defined in this topic, is in line with the historical era in historical definitions. According to the analysis of the ancient fabric materials found in archeology in Xinjiang, the unearthed woolen fabrics were mostly traced back to the prehistoric age, as earl as up to 2000 years ago.

\subsubsection{Space Category}

The ancient name of Xinjiang is Xiyu, meaning Western Region, which got the current name till the Qing Dynasty. Since the main materials of this thesis are the true objects unearthed in various archeological relics in the Xinjiang region, the spatial category of concern in this thesis specifically refers to the Geographic space area of today's Xinjiang Uygur Autonomous Region. Because these unearthed woolen fabrics from tombs are mainly distributed in the above eight geospatial spaces, this thesis will mainly focus on the eight geospatial zonings for study.

\section{Literature Review}

\subsection{Research Status at Home and Abroad}

\subsubsection{Domestic Research Status}

The research on the ancient woolen fabrics unearthed in Xinjiang has its historical documents that serve as the evidences for mutual verification along with the unearthed physical objects.

(1) Monographs on research of Chinese fabric patterns.

The development of ancient Chinese fabrics has a long history, which have reached a superlative level of technology, making them a wonder to the world. Therefore, the research in respect of the technologies and arts has never stopped. These treatises all have a discussion of the achievements of ancient weaving technology of Xinjiang and the characteristics of the patterns.

Monographs on woolen fabrics and their technologies are as follows: History of Science and Technology of China - Weaving (edited by Zhao Chengze) (Science Press, 2002), mainly discusses the production areas, weaving technologies, fabric types and patterns of Chinese fabrics, which also contains relevant content refers to and discusses the fabrics unearthed in Xinjiang that are well preserved till today. Among books devoted to studying the dyed patterns and the history, there are two masterpieces, History of Chinese Patterns and History of Chinese Dyeing and Weaving by Mr. Tian Zibing and Mr. Wu Shusheng respectively, which are the famous historians of arts and crafts in the country. Although the contents and focuses of these two books are different, but they are intrinsically linked, which provide some guidance to the study of this topic.

(2) Images and photograph atlas related to the ancient woolen fabrics unearthed Xinjiang.

The images and photograph atlases of woolen fabrics unearthed in Xinjiang published are one of the important basis for the study in the topic. These atlases were published at a large span of time, ranging from the 1950s till now, more than half a century. Among them, it is the book by the authors of Gao Hanyu and Bao Mingxin entitled Chinese Dying, Weaving and Embroidery Atlas (co-published by Commercial Press Hong Kong Branch and the Shanghai Science and Technology Press in October 1986). The book provides a comprehensive introduction of Chinese printing and dyeing, weaving and embroidery from three aspects, the history of development, technological progress, and graphic arts. It contains three hundred pieces of fine-selected pictures, most of which were first published at the time, of which one fifth of the content was contributed to the woolen fabrics unearthed in Xinjiang. This has important appreciation and reference value for the study.

Local archeology research institutes of Xinjiang also published a lot of atlases about ancient woolen fabrics unearthed in Xinjiang, which also become the main reference for future researchers. One of them is the Unearthed Artifacts in Xinjiang, edited by Museum of the Xinjiang Uygur Autonomous Region (published by Cultural Relics Publishing House in 1975) It cited 8 pieces of woolen fabrics unearthed in Xinjiang. Another one is Ancient Arts of Xinjiang, China, edited by Mu Shunying with Qi Xiaoshan, and Zhang Ping as deputy editors (Xinjiang Art Photography Press, 1994). The book is divided into catalog and description (in Chinese and English). The chapter titled Fabrics mainly introduces 45 pieces of woolen fabrics. Is a good reference for the study of patterns. 
There are atlases on the cultures related to Xinjiang region, such as Grand View of Xinjiang Artifacts and Relics edited by Xinjiang Cultural Relics Bureau (published by Xinjiang Art Photography Press, 1999). The cultural relics pictures published in the book all come from the cultural relics in Xinjiang. In this book, most of the images selected are pictures of the artifacts from tombs and ruins, which are the most important and best-illustrative ones, and therefore these pictures are representative and, of course, unearthed ancient wool artifacts are included. As the thesis part, Colorful Xinjiang Unearthed Fabrics by Mr. Wu Min focuses on the classification and characteristics of the wool and silk fabrics unearthed, which also describes the physical evidences as the exchanges of fabrics between China and West along the ancient Silk Road. Silk Road - Xinjiang Ancient Culture by Qi Xiaoshan and Wang Bo (Xinjiang People's Publishing House, 2008), is compiled in the way similar to Grand View of Xinjiang Artifacts and Relics, which mainly takes the three routes of the Silk Road in Xinjiang as the main lines, the South Road, Middle Road and North Road, and for each line 12 important tombs, ruins, Buddha towers, etc. are selected for key introduction. It also contains some new pictures of wool artifacts, which greatly enriched the subject content with the new materials. The thesis part of the book also contains a paper on fabrics unearthed in Xinjiang. Brief on Unearthed Wool and Silk Fabrics in Xinjiang is a book by Li Wenying, an associate researcher. On the research of woolen fabrics, the book mainly focuses on the period from prehistoric 4000 to the Han and Jin Dynasties, which provides quite objective analysis of the structure, dyeing, patterns and colors of the woolen fabrics unearthed in tombs of Zagunluk in Qiemo County and Shanpula in Luopu County. It serves as good model from the topic research.

In addition, it is very noteworthy that many relevant articles edited by Mr. Zhao Feng such as New Discovery of Fabric Archeology, which systematically expounded the research findings of Chinese fabric archeology. Wherein, the Xinjiang section introduced the fabrics newly unearthed from Niya, Yingpan and Keriya ruins, mainly wool and silk fabrics. The book entitled Silk Road Artifacts Unearthed Niya Site - Legacy of the Desert Prince (Yishatang/Costume Task Force, published in 2000). Made analysis and research on the precious cultural relics unearthed from No. 3 and No. 8 joint male and female tombs were unearthed in 1995 at the Niya royal cemetery. Wherein, there are 60 pictures of fabric artifacts, mostly clothing, apparel and household weaving articles. The above-mentioned atlases of the ancient fabric artifacts unearthed in Xinjiang contain repeated contents, which need further screening.

(3) Journal articles on Xinjiang Archeology of woolen fabrics (including fabric archeology and fabric art archeology)

The archeology of woolen fabrics in Xinjiang has always been an important part of China's fabric archeology, drawing attentions of both Chinese and foreign scholars. In this aspect, the research articles on ancient woolen fabrics unearthed in Xinjiang were mainly published in academic journals such as Cultural Relics, Xinjiang Cultural Relics, Turfan Studies, Xiyu Studies, and Dunhuang Studies. Here these articles are divided into two categories: The first category is the study of woolen fabrics excavated from burial sites in a certain area of Xinjiang. The second category is the research mainly based on the patterns of ancient woolen fabrics unearthed in Xinjiang.

The first category covers the ancient woolen fabrics unearthed in a certain area in Xinjiang.

Most of the woolen fabrics unearthed in Xinjiang were from prehistoric era, mostly woolen tabby, woolen twill, woolen tapestry, and woolen carpet. Specific relevant research includes Brief Talk About Woolen Fabric Unearthed in Niya Site by Jia Yingyi. This article talked about the classification of woolen fabrics unearthed from Niya Site at an earlier stage and the local production of woolen fabrics from the point of view on the physical objects. She has another article entitled Characteristics of Woven Woolen Garments Unearthed at Shanshan Yanghai Cemetery, which shows that the woolen fabrics unearthed in the Yanghai cemetery has many characteristics in common with that unearthed in other areas of Xinjiang. However, there are also some distinguished parts in comparison to those from other areas in Xinjiang, which have their own characteristics. For instance, the diversity of the basic tissue of the woolen tapestry and its pattern expressions.

Research of Woolen fabrics Newly-unearthed in Xinjiang by Wu Min drew an conclusion that the 14 specimens in three categories were not local products despite they were from Xinjiang. In fact, their origins were Central Asia and West Asia to west of Xinjiang. It is of far-reaching significance that these woolen fabrics were introduced to China while the Chinese silk fabrics were exported to the west.

In the Archaeological Discoveries and Studies of Yingpan Cemetery, written by Li Wenying and Zhou Jinling, provided quite detailed description of the excavations of the Yingpan cemetery. The article mentioned that a large number of fabric products were unearthed from the Yingpan Cemetery, which were classified into four categories by materials: silk, wool, cotton and hemp, of which the first two categories account for more than one 
third of the total number of unearthed relics. The pattern types are also very abundant.

Newly Discovered Fabrics of Han and Tang Dynasties on the Silk Road is an article that talks about the fabrics unearthed in Xinjiang ahead of the peers. In combination with the background of the development of the ancient Silk Road, this paper explores the fabrics of Han and Tang Dynasties newly-unearthed in the period of 1959 to 1969 from Wuwei, Dunhuang along Hexi Corridor in Gansu Province, Minfeng and Yutian on the South Road of Xinjiang, to Turpan and Bachu on the North Road. It mainly introduced the fabrics unearthed from different tombs in the six places and the patterns characteristics.

The second category is the research mainly focusing on the patterns of ancient woolen fabrics unearthed in Xinjiang.

Exploration of the Artistic Styles of the Symmetric Patterns of Fabrics Unearthed in Turpan, authored by Yin Fulan, sets the starting point on the very original and fine symmetric patterns on the fabrics unearthed in Turpan region to discuss the different composition forms of the symmetric patterns from different points of view.

Mythology Motif of Patterns of the Woolen Fabrics Unearthed in Yingpan Ancient Tombs in Xinjiang by Wu Yanchun sets the starting point on the theme of Eurasian mythology to make explorations the wool fabric patterns in term of origin of the art and culture awareness; such as the mythology and variants of the Human-animal Tree Pattern, the mythological philosophy conceived in the Volute Rhomboic Tree Pattern. He has another article, entitled Art of Ancient Animal Patterns in Xinjiang, analyzing the rise and fall of animal patterns in ancient times in the manner of dynasties.

Study on the Knotted Carpets of Shampula in Xinjiang by Qi Xiaoshan introduced five knotted carpets in the early of ancient Khotan era. Although the article only gives the basic information and pictures of these knotted carpets, but undoubtedly provides very good new materials for research on the ancient woolen fabrics unearthed in Xinjiang.

The Ornamental Trousers from Sampula (Xinjiang, China): Their Origins and Biography, authored by Wang Mu and Wang Bo, sets the study object on the Knifeerbockers with Centaur and Warrior Design (type B:84LS I M01:c162) unearthed in Shanpula, providing a detailed analysis of its background and the art characteristics of the patterns. The vivid description of the trousers displays the dynamic life of Central Asian residents at the end of the first millennium BC.

In addition, there are also studies on the development of the ancient weaving handicraft industry in Xinjiang, for example, Handicraft Industry in the Kingdom of Gaochang Huihu Kingdom by Jin Chunhong, which set the basis on the archaeological discoveries since the 20th century and the records of the relevant literature, makes analysis of the development of handicraft industry in the Gaochang Huihu Kingdom in the North Song and South Song Dynasties, including the discussion of the weaving and fur industries and the processing technology; in addition to the cotton industry, the silk and wool industries also existed in the Kingdom of Gaochang Huihu, which is also a developed area of silk industry in Xiyu region. On the Development of Ancient Wool Fabric Industry in Xinjiang by Jia Yingyi discussed the development of wool fabric industry in ancient Xinjiang based on the woolen fabrics unearthed therein. It expounded the wool weaving is the traditional handicraft industry in Xinjiang, from which the technical characteristics and pattern features formed have been used for a long time in the subsequent silk and cotton industries, which have become the traditional characteristics of Xinjiang textiles. Ma Guorong has discussed the wool weaving industry in his paper entitled Handicraft Industry in Xinjiang in the Han Dynasty, which asserts that the wool weaving industry in Xinjiang in the Han Dynasty was closely related to the animal husbandry that had reached a high level. The types of ancient fabrics unearthed in Xinjiang basically reflect the development of the fabric art in our country, which enrich the treasure house of ancient Chinese fabric specimens, providing a large amount of image materials for the study of fabric art and the cultural exchange between China and foreign countries.

(4) Relevant archaeological briefings and archaeological reports.

Since the ancient woolen fabrics unearthed in Xinjiang are taken as the research object, then the relevant archaeological briefings and archeology reports are very important first-hand information. For example, the Briefing of Excavation of the Cemetery in Turpan, and the Briefing of Excavation of Zagunluk Ancient Tombs in Qiemo Country, there are quite a large number of briefings.

The archaeological reports include Xinjiang Archaeological Excavation Reports 1957-1958, Thirty Years of Archeology in Xinjiang, New Achievements of Artifacts Archeology in Xinjiang 1979-1989, New Achievements of Artifacts Archaeology in Xinjiang (Continued) 1990-1996, etc., they provide the important data and physical images of archaeological discoveries, serving as the most direct first-hand information for follow-up studies. 
New breakthroughs have been made in archeology and scientific research in Xinjiang with new fields of research opened up, new explorations made, and important scientific achievements attained. Shanpula Xinjiang, China: Revelation and Study of Ancient Civilizations in Khotan sorted out all the cultural relics unearthed in Shanpula according to categories with detailed description one by one. In particular, the clothing chapter categorized 207 pieces of clothing artifacts unearthed in good state from Shanpula into wool fabric, silk fabric, cotton fabric, felt product and leather product with text messages and photos. Among the few the few archeological publications in Xinjiang, it provided first-hand reliable materials for studying the fabric artifacts unearthed in Xinjiang.

(5) Academic activities

Researches on the Silk Road and fabrics of the Silk Road have never been interrupted. A variety of academic activities are taken here and there, including the international conferences that focus on archeology, such as the international conferences with different themes organized by Turpan Academy of Sciences. There are also forums mainly focusing on archeological arts generally held by universities, such as a series of forums hosted by Donghua University focusing on the art and life, images and history of the Silk Road. And the professionals, experts and scholars invited to participate in these activities will publish their research papers on the conference and forums, and then published in a book by the conference organizer.

Through the review of the above literatures, it is fully proved that the research on the patterns of ancient woolen fabrics unearthed in Xinjiang is diversified, and the topic of each researcher has his own focus. However, there are few researches on the overall setting of the patterns of ancient woolen fabrics unearthed in Xinjiang, so space for research still exists, for example, the deep research on the origin of wool fabric patterns. The researches of these professionals and scholars also provide the basic reference for the research of this topic.

\subsubsection{Foreign Research Status}

As an important part of the ancient Silk Road, Xinjiang has its special geography and climate, which makes it possible to reserve a considerable amount of burial clothing and fabrics in good state up to nowadays. Because of this, the large number fabrics unearthed in Xinjiang have always been the focuses and points of interest of professionals and scholars both at home and abroad.

The archaeological data related to the study of Xinjiang was shown as early as in the relevant papers, archeological travel and diaries of foreign explorers. Such as Serindia and Ruins of Desert Cathay by M. Aurel Stein (from UK); Silk Road by Sven Hedging (from Sweden), Xinjiang Archeology by Bergman (from Sweden), and the Travel of Tachibana Zuicho by T. Zuicho (from Japan). These explorers and archaeologists have a certain historical significance in the excavation of cultural relics and historic sites on the Silk Road in western China. Although today many of these artifacts have been scattered in museums and private hands all over the world, many ancient woolen fabrics unearthed in Xinjiang are among them.

In addition, there are also articles on the study of specimens and patterns of fabrics from China, Eurasia and Central Asia, such as Review Publishing Company: Oriental Rugs and Carpets, which describes the history of oriental carpets in the most straightforward English language. It introduced the special knotting method for fixing the carpet suede; it revealed the symbolic meaning hidden in the carpet patterns, and provides comparison of the carpets (in terms of size color, pattern, texture, etc.) from Turkey, Persia, the Caucasus, India, and China.

There is a paper focusing on the study of the history of Xinjiang and its unearthed ancient fabrics is Ancient Xinjiang Between Central Asia and China; The Nomadic Factor by Nicola Di Cosmo, which discussed the flowing elements displayed in the relationship of ancient Xinjiang with Central Asia and the other regions of China, which further analyzed its particularity due to its location on the Silk Road. Silk Road to Sinkiang by Lqbal M. Shafi analyzed the important role played by Xinjiang on the Silk Road in trades from a historical perspective.

There are papers devoted to profound studies of Islamic fabric art, such as Embroideries \& Samplers from Islamic Egypt, and Woven Treasures: Textiles from the World of Islam by Marianne Ellis, Ashmolean Museum. Both papers analyzed the characteristics of Islamic style fabrics and their patterns from different perspectives.

Regarding the cultural studies of the Silk Road, in addition to the archeological excavations conducted in Xinjiang by several archaeological explorers previously described, L. Bourbonois, a famous French scholar, also talked about the Silk Road in his book: The Silk Road, which covers the relevant issues such as the hometown of silk, the road for silk trade and the trading ethnic, religious exchanges, Kangju: the country of traders and arts, and the influence of Rome on Central Asia. It gave detailed description of the generation of the Gandhara art and its impact on China, especially on the Western Regions. 


\section{Summary}

As a hub of the Silk Road, Xinjiang is the intersection of gathering and merging various cultural factors of East and West, while the wool fabric artifacts found along the Silk Road in the region have always been an important link in the study of the Silk Road. In general, some important achievements have been made in the study of ancient woolen fabrics unearthed in Xinjiang. However, research on the origin of the system wool fabric patterns is relatively weak, which is in urgent need to strengthen the research on the fabrics of the Silk Road. Therefore, it is important to take the woolen fabrics unearthed in Xinjiang as the research specimens to find out the inter Therefore, relationship through generalization, analysis and summarization of the patterns, and to find out the influence on the development of ethnic patterns in Xinjiang today.

\section{References}

Aliya. (1998). Study on Hand-painted Patterns of Woolen Fabric Unearthed in Zagunluk Cemetery in Charchan County of Xinjiang in 1985. Cultural relics of Xinjiang.

Binghua, W. (2009). Archaeology Research of the Silk Road. Urumqi: Xinjiang People Publishing House.

Feng, Z. (2002). Recent Excavations of Textiles in China. Hong Kong: ISAT/Costume Squad Ltd.

Feng, Z. (2008). Western Imprimts Textiles from Han and Jin Dynasties in China. Hong Kong:ISAT/Costume Squad Ltd.

Hanyu, G., \& Mingxin, B. (1986). Chinese Patterns through the Ages. Hong Kong: The Commercial Press, Ltd., HongKong Branch and Shanghai: Shanghai Scientific and Technical Publishing House.

Shunying, M. (1994). The Ancient Art in Xinjiang, China. Urumqi: Xinjiang Art Photography Publishing House.

Xiaojuan, M. (2014). Study on Geometric Pattern of Unearthed Woolen Fabric from Xinjiang. Advances in Textile Engineering and Materials IV, Advanced Materials Research, 1048, 318-321.

Xiaoshan, Q., \& Bo, W. (2008). The Ancient Culture in Xinjiang along the Silk Road. Urumqi: Xinjiang People's Publishing House.

Xinjiang Institute of Archaeology, Xinjiang Uygur Autonomous Region Museum. (1999). A Grand View of Xinjiang's Cultural Relics and Historic Sites. Urumqi: Xinjiang Art Photography Publishing House.

Xinjiang Uygur Autonomous Region Museum, Xinjiang Institute of Archaeology. (2001). Sampula in Xinjiang of China. Urumqi: Xinjiang People's Publishing House.

Xinjiang Uygur Autonomous Region Museum. (1973). The Textiles from Han and Tang Dynasties Along the Silk Road. Beijing: Cultural Relics Publishing House.

Xinjiang Uygur Autonomous Region Museum. (1975). The Unearthed Cultural Relics in Xinjiang. Beijing: Cultural Relics Publishing House.

Xinjiang Uygur Autonomous Region Museum. (2010). Costume Essence in Ancient Western Regins. Beijing: Cultural Relics Publishing House.

\section{Copyrights}

Copyright for this article is retained by the author(s), with first publication rights granted to the journal.

This is an open-access article distributed under the terms and conditions of the Creative Commons Attribution license (http://creativecommons.org/licenses/by/4.0/). 